\title{
Classifying the Thyroid Lesions on FNAC According to TBSRTC with Cytohistopathological Correlation
}

\author{
Dr. Manasi P. Trivedi MD ${ }^{1}$, Dr. Trupti S. Patel M.D., DCP ${ }^{2}$ \\ ${ }^{1}$ Department of Pathology, Gujarat Cancer \& Research Institute. Gujarat \\ ${ }^{2}$ Associate Professor, Department of Pathology, Gujarat Cancer \& Research Institute, Gujarat
}

\begin{abstract}
The objective of this prospective study was to analyze the thyroid cytology smears by The Bethesda System for Reporting Thyroid Cytopathology (TBSRTC), to analyze cytological features, and to correlate the cytopathology with its histopathology. Stastical analysis was done. Possible reasons for false positive and false negative results were discussed. Out of 103 fine needle aspirations (FNA) of thyroid nodules, $11.7 \%$ nondiagnostic/unsatisfactory (ND/UNS), $20.3 \%$ benign, $10.7 \%$ atypia of undetermined significance/follicular lesion of undetermined significance (AUS/FLUS), 9.7\%, follicular neoplasm/suspicious of a follicular neoplasm(FN/SFN), 11.7\% suspicious for malignancy (SFM), and 35.9\% malignant. So, it was concluded that TBSRTC is not only useful method for standardization the reporting of thyroid cytopathology but also provides clear management guidelines to clinicians whether to go for follow-up FNA or to do surgery. Thus, unnecessary surgery will be avoided.
\end{abstract}

Short running title: Thyroid lesions according to TBSRTC

Keywords: TBSRTC, histology, FNAC, thyroid

\section{Introduction}

After diabetes mellitus, the thyroid gland is the most common organ to cause endocrine disorders. ${ }^{1}$ Thyroid carcinoma closely resembles its benign counterpart. A solitary thyroid nodule is more concern because of high probability of malignancy ranges from 5-35\%. ${ }^{2}$ Therefore, the surgical excision of the nodule and its histological examination is the only way to differentiate between benign and malignant nodules. In spite of great advances in the understanding of thyroid malignancies various types and their aggressiveness continue to complicate both diagnosis and management. In India, there are 216,000 new cases of thyroid malignancies per year ${ }^{3}$ and hence the role of properly evaluating thyroid lesions is significant. Fine Needle Aspiration Cytology (FNAC) has proven to be a first line tool to evaluate the thyroid lesions because of its cost effectiveness and high patient acceptance and is highly successful in triaging patients with thyroid nodules into operative and non-operative groups. Thus, enables surgeons to take an early decision regarding mode of treatment to be applied. Though, thyroid FNAC is highly sensitive technique, there has been wide variation and subjectivity in the interpretation and reporting of uncertain categories by different institutions which led to inconsistent practices among pathologists and clinicians. ${ }^{4}$ Until recently, there were no uniform criteria established for the various diagnostic categories and specimen adequacy. Various terminologies like "atypical," "indeterminate," and "suspicious for malignancy," were used. In an attempt to establish a standardized diagnostic terminology classification system and morphologic criteria for reporting thyroid FNAs, the National Cancer Institute (NCI) hosted "The NCI Thyroid Fine Needle Aspiration State of the Science Conference" at Bethesda, Maryland. There were six committees which dealt with different areas regarding thyroid cytology. Committee IV dealt with diagnostic terminology and morphologic criteria for cytological diagnosis of thyroid lesions. Its recommendations were widely published. ${ }^{5}$ Subsequently a monograph "The Bethesda System for Reporting Thyroid Cytopathology" (TBSRTC) which includes definitions, diagnostic/morphologic criteria, explanatory notes, and a brief management plan for each diagnostic category was published. ${ }^{6}$ TBSRTC has well- defined and rational management algorithms with implied risk of malignancy in each of the six diagnostic categories. ${ }^{4,7}$ Each category has an implied cancer risk, which ranges from $0 \%$ to $3 \%$ for the "benign" category to virtually $100 \%$ for the "malignant" category.

The aim of the present prospective study, was to start reporting the thyroid cytology smears by TBSRTC into various diagnostic categories and to assess its efficacy, to analyse cytological features and correlate them with histology of surgical specimens received.

\section{Material \& Methods}

This is a prospective study of thyroid FNACs accrued over a period of 2 years, from 2014 to 2016. These smears were collected from patients with signs and symptoms of various thyroid lesions, who presented to the M.P.Shah Cancer Hospital, Gujarat, India. Related clinical history including physical examination, radiological findings and laboratory investigations were noted. Patients with past history of thyroid malignancy and/or FNAC cases which were not followed surgically were excluded from study.

Fine needle aspiration cytology was performed in the Cytology section of Pathology Department, G.C.R.I, Ahmedabad after taking verbal consent. FNA was done with

\section{Volume 6 Issue 12, December 2017}




\section{International Journal of Science and Research (IJSR) \\ ISSN (Online): 2319-7064}

Index Copernicus Value (2016): 79.57 | Impact Factor (2015): 6.391

needle (22 or 24 gauze) by non-aspiration technique. In cystic swelling, fluid was aspirated as much as possible. Repeat FNA was done from firm area if necessary. Five or six smears were prepared. One smear was air dried and stained by May-Grunwald Giemsa stain. Remaining smears were quickly fixed with $100 \%$ methanol and stained with Modified Papanicolao stain. All the smears were thoroughly examined and diagnosis was done on the basis of the newly proposed Bethesda System of Reporting Thyroid Cytopathology (TBSRTC). ${ }^{6}$ (Table:1) The thyroid specimen were fixed in $10 \%$ formalin. Representative tissue bits were taken. Histopathological specimens were processed as per standard methods. Blocks were stained with routine Hematoxylin and Eosin (HE) stain. The final diagnoses were determined by the reports of surgical pathology.Cytologichistologic correlation were done. Histology reports were considered as gold standard for final diagnosis and also for future management. Approval was sought from the institute's ethics committee which approved the current study.

Statistical analysis: Diagnostic yield, diagnostic accuracy, sensitivity, specificity, positive predictive value, and negative predictive value were calculated using histopathology diagnosis as gold standard. For calculating statistical parameters ND/UNS and AUS/FLUS cases were excluded. Categories "SFM" and "malignant" were considered as malignant and put together. The concordance and discordance rates were also calculated.

\section{Observation \& Results}

Fine needle aspiration cytology was performed on total 401 patients with various thyroid lesions. Out of the 401 FNAs, 103 were operated in-house, thus were included in the study. Age ranged from 8 to 75 years. Mean age was 42.68 years. Female to Male ratio was 2.96:1. Out of 103 cases, $12(11.7 \%)$ were in diagnostic category I(ND/UNS), $21(20.4 \%)$ were diagnostic category II(Benign), 11(10.7\%) were in diagnostic category III(AUS/FLUS), 10(9.7\%) were in diagnostic category IV (FN/SFN), 12(11.7\%) were in diagnostic category $\mathrm{V}(\mathrm{SFM})$ and $37(35.9 \%)$ were in diagnostic category VI(Malignant). Out of 103 cases, 24 cases had hemi-thyroidectomies, 3 had subtotal thyroidectomies and remaining 76 had total thyroidectomies. Histology - cytology correlation was shown in Table:2. Of the 12 cases of ND/UNS, smears of 3 cases had low cell content, in 6 cases had cyst fluid with or without histiocytes, while remaining 3 cases revealed presence of blood obscuring the thyroid follicular cells. Out of 21 cases ofbenign lesion, 19 cases were sub categorized as Benign Follicular Nodules and 2 cases given as Hashimoto's thyroiditis. In AUS/FLUS category, 4 cases showed predominant population of Hürthle cells, 5 cases showed focal nuclear features suggestive of papillary carcinoma, one case showed microfollicular pattern in an otherwise predominantly benign appearing samplesand last single case showed follicular cell nuclear atypia hindered by air drying artifact. FN/SFN included 10 cases out of which only single case showed hurthal cell morphology. Out of 12 cases of SFM 10 cases showed featured suggestive of SFM for papillary carcinoma and remaining two cases showed SFM featured suggestive of medullary carcinoma. In malignantcategory, 30 cases showed features of papillary carcinoma, 3 of medullary carcinoma, 2 of anaplastic carcinoma and one case each of primary Lymphoma and primary thyroid carcinoma-NOS type in total of 37 cases.

\section{Discussion}

Thyroid nodules are common clinical findings and have a reported prevalence of 4-7\% of the adult population, however fewer than 5 percent of adult thyroid nodules are malignant. ${ }^{9}$ Fine needle aspiration biopsy is extremely helpful in the diagnosis of various thyroid lesions including goiter, thyroiditis and neoplasms. This extremely useful cost-effective, minimally invasive worldwide technique helps to avoid unnecessary thyroid surgery. The recently introduced and much anticipated Bethesda System for Reporting Thyroid Cytopathology (TBSRTC) has standardized cytomorphological criteria for diagnosis and adequacy of specimen. It has well- defined and rational management algorithms with implicit risk of malignancy in each of the 6 diagnostic categories. A uniform reporting system for thyroid FNA will facilitate effective communication among clinician and cytopathologist, and also allow easy and reliable sharing of data from different laboratories for national and international collaborative studies. Since the publication of TBSRTC, it has been widely used and articles implementing TBSRTC have started appearing in the literature. , $^{9,10,11,12,13}$

In the present study we also share our experience in reporting FNA of thyroid by TBSRTC with its correlation with histology in an Indian academic institution. The diagnostic yield of FNA cytological results according to TBSRTC from our Institute was $88.3 \%$ overall, the sensitivity was $95 \%$ and specificity was $90 \%$ to diagnose malignancy on routine cytology. These results were comparable to the other studies. ${ }^{14-22} \mathrm{We}$ had $11.7 \%$ cases in ND/UNS group and $20.3 \%$ in benign group.Other studies had a range of $1.2 \%$ to $18.6 \%$ cases in first group and $34 \%$ to $87.5 \%$ in "benign" category. An AUS/FLUS group of thyroid has been reported in the range of $1-29 \%$ and FN/SFN group had a range of $2.2-16.1 \%$. We had $10.7 \%$ in AUS/FLUS group and $9.7 \%$ in FN/SFN. SFM category varies from 1.3 to $10 \%$ and malignant group had a range of $2.9 \%$ to $11 \%$. We had $11.7 \%$ for SFM and $35.9 \%$ in malignant group. These results are comparable to the previously published studies. ${ }^{4,7,8,23,24}$ Risk of malignancy in our study was $41.7 \%$ for ND/UNS, $14.3 \%$ for benign, $54.5 \%$ for AUS, $60 \%$ for FN/SFN, 91.7\% suspicious for malignancy and $97.3 \%$ for malignant lesion. As compare to the published data we had more percentages of risk of malignancy. ${ }^{4,7,8,23,24}$ Our hospital is the regional cancer centre. Many begin thyroid conditions filtered out at lower centres,so we had mainly the specimen of malignant cases. Out of 401 FNACs only 103 cases were operated in house.

In the literature ${ }^{15,16,18,21}$ accuracy rate ranged from $86.1 \%$ to $98 \%$. In the present series, we obtained $93.75 \%$ by routine cytological reporting. The false positive rate ranged from 0.2 to $11.1 \%$ and the false negative rates ranged from $1.4 \%$ to $44.7 \%$ in the series of various workers. ${ }^{15-21}$ In our study, the false positive rate was $2.5 \%$ and false negative rate was $3.75 \%$. Possible reasons were: a) Cellular atypia due to 


\section{International Journal of Science and Research (IJSR) \\ ISSN (Online): 2319-7064}

Index Copernicus Value (2016): 79.57 | Impact Factor (2015): 6.391

hyperplastic reaction in adenoma, b) sampling inadequacy leads to the misdiagnosis in sclerosed/fibrous areas of tumors like anaplastic carcinoma and papillary carcinoma, c) untrained pathologists performing the sampling procedure, d) cellular material with 3-D clusters e) microfollicular pattern with focal nuclear features of PTC were the major reasons for our discrepancy. Repeat FNAC after 3 months interval was suggested in category I cases, but because of clinical indications surgery was done. Suen KC and Quenville $\mathrm{NF}^{33}$ concluded that the common false positives were a) Cellular colloid goitre mistaken for neoplasm, b) Thyroiditis mistaken for lymphoma and c) Cellular atypia due to hyperplastic reaction in adenoma. False negatives are due to misdiagnosis of papillary and follicular carcinomas as goiters' lesion. ${ }^{17}$ The difficulty in distinguishing follicular carcinoma from its benign counterpart was experienced even in histological sections since capsular and vascular invasion are essential for the diagnosis of malignancy, which cannot be demonstrated on cytology. Committee V of the NCI Thyroid Fine Needle Aspiration State of the Science Conference has provided guidelines for indications of ancillary studies, specific ancillary studies to be performed, and sample preparation for each study. Following immunohistochemistry panels have been suggested for suspicious malignancies. Calcitonin, thyroglobulin, CEA, and chromogranin for medullary carcinoma, pan-cytokeratin for anaplastic carcinoma, and TTF-1 for metastatic carcinoma. These are to be done on cell block from FNA, preferably including at least one dedicated pass for the study. For suspicious of lymphoma, flow cytometric immunophenotyping is suggested. Dedicated passes are also needed for studies to detect genetic alterations such as BRAF mutation or RET/PTC chromosomal rearrangements, which are very promising for the diagnosis of papillary carcinoma. Immunocytochemistry on cytospin, direct smear, or prefixed monolayer may also be utilized, but protocols should be carefully validated. ${ }^{34}$

This study inferred that TBSRTC using the Bethesda monograph is a very useful method for standardization the reporting of thyroid cytopathology. The monograph is succinctly written in an easy-to-read format and has useful colour images which help in making the diagnosis and to reduce inter-observer variability. TBSRTC also mentioned implied risk of malignancy to specific diagnostic categories and recommends the clinical management and thus, improving the communication between clinicians and cytopathologists for more consistent management approaches.

\section{Acknowledgements}

We express our gratitude towards Dr.DhavalJetaly, Head of Department and Dr. R.K. Vyas, Director of GCRI for providing the infrastructure and resources to complete my dissertation work. We would like to thank the technical staff members of the Cytopathology and Histopathology laboratory.

Table 1: The Bethesda System for Reporting Thyroid Cytopathology: Recommended DiagnosticCategories.

\section{Nondiagnostic or Unsatisfactory}

Cyst fluid only

Virtually acellular specimen

Other (obscuring blood, clotting artifact, etc.)

\section{Benign}

Consistent with a benign follicular nodule (includes adenomatoid nodule,

Colloidnodule, etc.)

Consistent with lymphocytic (Hashimoto) thyroiditis in the proper clinical context

Consistent with granulomatous (subacute) thyroiditis

\section{Atypia of Undetermined Significance or Follicular Lesion of Undetermined Significance}

\section{Follicular Neoplasm or Suspicious for a Follicular Neoplasm}

Specify if Hürthle cell (oncocytic) type

\section{Suspicious for Malignancy}

Suspicious for papillary carcinoma

Suspicious for medullary carcinoma

Suspicious for metastatic carcinoma

Suspicious for lymphoma

Other

\section{Malignant}

Papillary thyroid carcinoma

Poorly differentiated carcinoma

Medullary thyroid carcinoma

Undifferentiated (anaplastic) carcinoma

Squamous cell carcinoma

Carcinoma with mixed features (specify) 
International Journal of Science and Research (IJSR)

ISSN (Online): 2319-7064

Index Copernicus Value (2016): 79.57 | Impact Factor (2015): 6.391

Metastatic carcinoma

Non-Hodgkin lymphoma

Other

Table 2: Cytological-Histological Correlation of total 103 cases

\begin{tabular}{|c|c|c|c|c|c|c|c|c|c|c|}
\hline Diagnosis & Goiter & Hash. Thy. & Adenoma & $\mathrm{FC} / \mathrm{HC}$ & PC & MC & $\mathrm{AC}$ & NHL & PDC-Nos & Total \\
\hline ND/UNS & 5 & & 2 & & 4 & 1 & & & & 12 \\
\hline Begin & 17 & 1 & & 1 & 1 & & 1 & & & 21 \\
\hline AUS/FLUS & 3 & & 2 & & 6 & & & & & 11 \\
\hline FN/SFN & & & 4 & 4 & 1 & & & & 1 & 10 \\
\hline SFM-PC & 1 & & & & 9 & & & & & 10 \\
\hline SFM-MC & & & & & & 2 & & & & 2 \\
\hline PC & 1 & & & & 29 & & & & & 30 \\
\hline $\mathrm{MC}$ & & & & & 1 & 2 & & & & 3 \\
\hline $\mathrm{AC}$ & & & & & & & 2 & & & 2 \\
\hline NHL & & & & & & & & 1 & & 1 \\
\hline PDC & & & & & & 1 & & & & 1 \\
\hline Total & 27 & 1 & 8 & 5 & 51 & 6 & 3 & 1 & 1 & 103 \\
\hline
\end{tabular}

(Hashi. Thy - Hashimotos Thyroiditis, FC/HC- Follicular carcinoma/Hurthle cell carcinoma , PC- Papillary carcinoma ,MC- Medullary carcinoma ,AC- Anaplastic carcinoma, NHL- Nonhodgkins lymphoma, PDC- Poorly differentiated carcinoma , Nos- Not otherwise specified type)

\section{Prior publication- NO}

\section{Support- NA}

\section{Conflicts of interest- NA}

\section{Permissions- NA}

\section{Funding - NA}

\section{Reference}

[1] Gritzmann N, Koischwitz D, Rettenbacher T. Sonography of the thyroid and parathyroid glands.In: Weber AL, editor. The Radiologic Clinics of North America. 3rd ed. New York: Elsevier; 2000 .p. 113143.

[2] Ananthakrishnan N, Rao KM, Narasimhans R, Veliath, Smilet SR, Jagadish S. The Single Thyroid Nodule: A South Indian Profile of 503 Patients with Special Reference to Incidence of Malignancy. Indian J Surg 1993;55(10):487-92.

[3] Ghoshal B, Pal NC, Majumdar P. FNAB in the diagnosis of cold thyroid nodules: correlative study with histopathology and its application in thyroid surgery. J Indian Med Assoc 1984;18:127-9.

[4] Jo VY, Stelow EB, Dustin SM, Hanley KZ. Malignancy risk for fine needle aspiration of thyroid lesions according to the Bethesda System for Reporting Thyroid Cytopathology. Am J ClinPathol 2010;134(3):450-6.

[5] Baloch, Z. W., LiVolsi, V. A., Asa, S. L., Rosai, J., Merino, M. J., Randolph, G., Vielh, P., DeMay, R. M., Sidawy, M. K. and Frable, W. J. "Diagnostic terminology and morphologic criteria for cytologic diagnosis of thyroid lesions: a synopsis of the national cancer institute thyroid fine-needle aspiration state of the science conference," Diagnostic Cytopathology 2008;36(6): 425-37.

[6] S. Z. Ali and E. S. Cibas, Eds.The Bethesda System for Reporting Thyroid Cytopathology. Definitions, Criteria and Explanatory Notes, Springer, New York, NY, USA, 2010.

[7] Yang J, Schnadig V, Logrono R, Wasserman PG. Fineneedle aspiration of thyroid nodules: a study of 4703 patients with histologic and clinical correlations. Cancer 2007;111(5):306-15

[8] Yassa L, Cibas ES, Benson CB, Frates MC, Doubilet PM, Gawande AA, Moore FD Jr, Kim BW, Nosé V, Marqusee E, Larsen PR, Alexander EK. Long-term assessment of a multidisciplinary approach to thyroid nodule diagnostic evaluation. Cancer. 2007;111(6):508516.

[9] Sclabas GM, Staerkel GA, Shapiro SE, Fornage BD, Sherman SI, Vassillopoulou-Sellin R, Lee JE, Evans DB Fine Needle Aspiration cytology of the thyroid and correlation with histopatholgy in a contemporary series of 240 patients. Am J Surg 2003:186;702-9

[10] Bongiovanni M, Spitale A, Faquin W, C, Mazzucchelli L, Baloch Z, W, The Bethesda System for Reporting Thyroid Cytopathology: A Meta-Analysis. ActaCytologica 2012;56:333-339

[11] Layfield LJ, Abrams J, Cochand-Priollet B, Evans D, Gharib H, Greenspan F, Henry M, LiVolsi V, Merino M, Michael CW, Wang H, Wells SA. Post-thyroid F NA testing and treatment options: a synopsis of the national cancer institute thyroid fine needle aspiration state of the science conference. Diagnostic Cytopathology 2008;36(6):442-8.

[12] L. Q. Wong and Z. W. Baloch, "Analysis of the Bethesda System for reporting thyroid cytopathology and similar precursor thyroid cytopathology reporting schemes," Advances in Anatomic Pathology 2012;19(5):313-19

[13]B. K. Richmond, B. A. O'Brien, W. Mangano, S. Thompson, and S. Kemper, "The impact of implementation of the Bethesda system for reporting thyroid cytopathology on the surgical treatment of thyroid nodules," The American Surgeon 2012;78(6):706-10

[14] Silverman JF, West RL, Larkin EW, Park HK, Finley JL, Swanson MS, Fore WW. The role of fine-needle

\section{Volume 6 Issue 12, December 2017}




\section{International Journal of Science and Research (IJSR) \\ ISSN (Online): 2319-7064}

Index Copernicus Value (2016): 79.57 | Impact Factor (2015): 6.391

aspiration biopsy in the rapid diagnosis and management of thyroid neoplasm. Cancer 1986;57(6):1164-70.

[15] Singh P, Chopra R, Calton N, Kapoor R. Diagnostic Accuracy of Fine Needle Aspiration Cytology of Thyroid lesions. Journal of Cytology 2000;17(3):135-9.

[16] El Hag IA, Kollur SM, Chiedozi LC. The role of FNA in the initial management of thyroid lesions: 7-years' experience in a district general hospital. Cytopathology 2003;14(3):126-30.

[17] Sangalli G, Sergio G, Zampatti C, Bellotti M, Lomuscio G. Fine needle aspiration cytology of the thyroid: A comparison of 5469 cytological and final histological diagnosis. Cytopathology 2006;17(5):245-50.

[18] Mandal S, Barman D, Mukherjee A, Mukherjee D, Saha J, Sinha R. Fine needle aspiration cytology of thyroid nodules-evaluation of its role in diagnosis and management. J Indian Med Assoc 2011;109(4):258-61.

[19] Guhamallick M, Sengupta S, Bhattacharya NK, Basu N, Roy S, Ghosh AK, Chowdhury M. Cytodiagnosis of thyroid lesions-usefulness and pitfalls: A study of 288 cases. J Cytol 2008;25(1):6-9

[20] Ylagan LR, Farkas T, Dehner LP. Fine needle aspiration of the thyroid: cytohistologic correlation and study of discrepant cases. Thyroid 2004:14(1)35-41.

[21] Aravinthan T, Banagala ASK, Gamage KJPK. Use of fine needle aspiration cytology on thyroid lumps. Galle Medical Journal 2007;12(1):25-29

[22] Mistry SG, Mani N, Murthy P. Investigating the value of fine needle aspiration cytology in thyroid cancer. J Cytol 2011;28(4):185-90.

[23] Nayar R., Ivanovic M. The indeterminate thyroid fineneedle aspiration: experience from an academic center using terminology similar to that proposed in the 2007 National Cancer Institute Thyroid Fine Needle Aspiration State of the Science Conference. Cancer. 2009;117(3):195-202.

[24] Mondal SK, Sinha S, Basak B, Roy DN, Sinha SK. The Bethesda system for reporting thyroid fine needle aspirates: A cytologic study with histologic follow-up. J Cytol 2013;30(2):94-9.

[25]C. G. A. Theoharis, K. M. Schofield, L. Hammers, R. Udelsman, and D. C. Chhieng, "The bethesda thyroid fine-needle aspiration classification system: year 1 at an academic institution," Thyroid 2009;19(11):1215-23.

[26] Bonzanini M, Amadori PV, Morelli L, Fasanella S,Pertile R, Mattiuzzi A,Marini G, Niccolini M, Tirone G, Rigamonti M, Paolo Dalla Palma.Subclassification of the 'grey zone' of thyroid cytology; a retrospective descriptive study with clinical, cytological, and histological correlation," Journal of Thyroid Research 2011;DOI: $10.4061 / 2011 / 251680$

[27] J. T. Broome and C. C. Solorzano, "The impact of atypia/follicular lesion of undetermined significance on the rate of malignancy in thyroid fine-needle aspiration: evaluation of the Bethesda system for reporting thyroid cytopathology," Surgery 2011;150(6):1234-41.

[28] Al-Shraim MM, Kaood OM, Hussein MR, Al-Ahmary AM, Al Shehri GY, Jastania RA, Mahfouz AA, AbuEshy SA.Assessment of malignancy rate in thyroid nodules according to the Bethesda system of fine-needle aspiration: report from a tertiary center in the
Southwestern region of Saudi Arabia.Saudi Medical Journal 2012;33(2):167-71.

[29] Arul P., Akshatha C., Masilamani S. A study of malignancy rates in different diagnostic categories of the Bethesda system for reporting thyroid cytopathology: an institutional experience. Biomedical Journal 2015;38(6):517-22

[30] Krauss E. A., Mahon M., Fede J. M., Zhang L. Application of the Bethesda classification for thyroid fine-needle aspiration: institutional experience and meta-analysis. Archives of Pathology \& Laboratory Medicine. 2016;140(10):1121-31.

[31] Y. S. Choi, S. W. Hong, J. Y. Kwak, H. J. Moon, and E. K. Kim, "Clinical and ultrasonographic findings affecting nondiagnostic results upon the second fine needle aspiration for thyroid nodules," Annals of Surgical Oncology 2012;19(7): 2304-9.

[32] Bakshi N. A., Mansoor I., Jones B. A. Analysis of inconclusive fine-needle aspiration of thyroid follicular lesions. Endocrine Pathology. 2003;14(2):167-75.

[33] Suen KC, Quenville NF. Fine needle aspiration biopsy of the thyroid gland: a study of 304 cases. J ClinPathol 1983;36(9):1036-45

[34] A. C. Filie, S. L. Asa, K. R. Geisinger et al., "Utilization of ancillary studies in thyroid fine needle aspirates: a synopsis of the national cancer institute thyroid fine needle aspiration state of the science conference," Diagnostic Cytopathology 2008;36(6):438-41. 